\title{
Sequelas invisíveis dos acidentes de trânsito: o transtorno de estresse pós-traumático como problema de saúde pública
}

\author{
Invisible sequels of traffic accident: the post-traumatic stress disorder \\ as a public health problem
}

Fátima Gonçalves Cavalcante ${ }^{1}$

Patrícia Alessandra M orita ${ }^{2}$

Sonia Rodrigues $\mathrm{Haddad}^{3}$

\footnotetext{
${ }^{1}$ Centro Latino-Americano deEstudos da Violência e SaúdeJorge Careli, Escola Nacional de Saúde Pública,

Fundação Oswaldo Cruz. Av. Brasil 4036/700,

M anguinhos. 21040-361

Rio deJaneiro RJ.

fatimagold7x7@yahoo.com.br

${ }^{2}$ Instituto de Pesquisa

Econômica Aplicada.

${ }^{3}$ M inistério das Cidades.
}

\begin{abstract}
This document consolidates the results of the Seminar "Invisible Squeals of Traffic Accidents" carried out as part of the Project "Social and Economic Impacts of Traffic Accidents in Brazilian Highways". To begin with, the characteristics of post-traumatic stress disorder related to traffic accidents are identified, as well as its potential victims, symptoms, diagnosis, as well as risk and protection factors for the development of the disease. N ext, follows a brief description of projects and research developed in Brazil and abroad in the field. Finally, post-traumatic stress disorder isanalyzed as a matter of Public $\mathrm{H}$ ealth and policy recommendations are presented as a suggestion to reduce the sociopsychological consequences of traffic accidents violence.
\end{abstract}

Key words Post-traumatic stress disorder, Traffic accidents, Public health
Resumo Este documento consolida os resultados obtidos no Seminário "Sequelas invisíveis dos acidentes de trânsito", realizado no contexto do projeto "Impactos sociais eeconômicos dosacidentes detrânsito nas rodovias brasileiras". São identificadas características do transtorno de estresse pós-traumático decorrente de acidentes de trânsito, vítimas potenciais, sintomas, diagnóstico e fatores de risco e de proteção para o desenvolvimento do transtorno. Em seguida, são apresentados projetos e pesquisas realizadas no Brasil e no exterior sobre o tema. Finalmente, aborda-se o problema do transtorno de estresse pós-traumático sob a ótica da saúde pública e apresentam-se recomendações para políticas públicas voltadas para a redução dos impactos psicossociais da violência dos acidentes de trânsito.

Palavras-chave Transtorno de estresse pós-traumático, Acidentes de trânsito, Saúde pública 
Introdução

0 acidentedetrânsito éum problemagraveem todo o mundo. De acordo com estimativa apontada pela Organização Mundial de Saúde1, em torno de 1,2 milhão depessoasmorrem por ano em consequência de acidentes de trânsito nas rodovias. Os acidentes de trânsito são a segunda causa de morte entre jovens de 5 a 29 anos e a terceira causa de morte entre pessoas de 30 a 44 anos. Além dessas mortes, estima-se que, por ano, em torno de 50 milhões de pessoas saiam feridas ou incapacitadas, em decorrência de acidentes de trânsito nas rodovias.

No Brasil, em 2004, ocorreram 112.457 acidentes nas rodovias federais: uma média de 308 acidentes por dia ou aproximadamente treze acidentes por hora. Estima-se que esses acidentes provocaram mais de 10.000 mortes, tendo envolvido quase meio milhão de pessoas. Esses números tornam-se mais alarmantes quando contabilizados os acidentes ocorridos nas rodovias estaduais e municipais².

Vitimando também crianças e idosos, os acidentes, além de produzirem vítimas fatais, deixam sequel as de graus variados entre os sobreviventes e efeitos adversos entre os membros da família. Qual o custo social de uma criança que perde sua mãee/ ou seu pai num acidente? Qual o custo social de uma mulher ou de um homem que adquiriram uma deficiência gravequeirá afetar seu ajustamento pessoal, familiar e profissional, para além dos custos com resgate, assistência hospitalar, reabilitação, perda de produção, gastos previdenciários, danos a terceiros, administração de seguros e suporte de agentes de trânsito? Q uais as sequelas invisíveis dos acidentes de trânsito?

Essa realidade impeliu a uma análise mais cuidadosa do estresse pós-traumático decorrente de acidentes de trânsito no contexto do projeto "Impactos sociais e econômicos dos acidentes de trânsito nas rodovias brasileiras"2. Reunindo especialistas, do Brasil e do exterior, o Instituto de Pesquisa Econômica Aplicada (I pea) promoveu um seminário na O rganização Pan-Americana de Saúde (OPAS), em junho de 2006, para discutir econsolidar experiências que pudessem caracterizar o problema, homogeneizar conceitos e gerar recomendações de políticas públicas para a redução dos impactos negativos psicossociais da violência dos acidentes de trânsito.

0 objetivo deste estudo é consolidar os resultados obtidos nesse seminário, "Sequelas invisíveis dos acidentes de trânsito", e propor políticas públicas para o tratamento do tema. A primeira parte trata da caracterização do transtorno de estresse pós-traumático (TEPT): são descritas as características da patologia, vítimas, sintomas, diagnóstico, além de fatores de risco e de proteção para o desenvolvimento do transtorno. Em seguida, são apresentados projetos e pesquisas realizadas no Brasil e no exterior sobre o TEPT. Na terceira parte, aborda-se o problema do TEPT sob a ótica da saúde pública e, por fim, apresentam-se recomendações para políticas públicas voltadas ao tema.

Transtorno de estresse pós-traumático decorrente de acidentes de trânsito

Esta seção baseou-se no estudo sobre 0 estresse associado a acidentes de trânsito apresentado no seminário "Sequelas invisíveis dos acidentes detrânsito" pelas professoras portuguesas da Universidade do M inho, M aia e Pires ${ }^{3-5}$.

\section{Caracterização}

A reação a situações de estresse é uma resposta neuroquímica e neurofisiológica do cérebro ao perceber que está em perigo. Trata-se de uma resposta fisiológica com liberação de hormônios e que nos permite sobreviver, sendo uma resposta extremamente adaptativa e adequada. Ela engl oba o aceleramento dos batimentos cardíacos e a contração de músculos, por exemplo.

No organismo de uma pessoa sadia, ocorre um pico de estresse, com um pico de hormônios de estresse. Quando a situação se normaliza, cessa a liberação de hormônios e segue-se a vida adiante. Contudo, diante da exposição a situações de grandeestresse, deestresseacumulado, como quem viveviolência doméstica, como quem tem uma história precoce nos primeiros anos de maus-tratos, de abuso ou de negligência, o sistema de regulação de estresse pode sofrer graves alterações 3,6-10.

0 transtorno de estresse pós-traumático é uma síndromequepodedecorrer da exposição a um trau$\mathrm{ma}^{3,6-8}$. Conceitualmente, um trauma resulta de:

. experiência pessoal de acontecimento que envolva morte ou ameaça de morte, ferimento grave ou ameaça à integridade física;

- testemunhar um acontecimento que envolva morte, ferimento ou ameaça à vida de outra pessoa;

- ter conhecimento demorteinesperada ou violenta, ferimento grave ou ameaça de morte, ou doença grave num familiar próximo.

Envolve também respostas de medo intenso, impotência ou horror.

Os acidentes de trânsito tornam-se acontecimentos traumáticos quando há percepção de amea- 
ça à vida; quando há confronto com o sofrimento ou com a morte deoutros; ediante deacontecimentos repentinos de impacto extremo, gerados por causas externas, que desencadeiam respostas de medo intenso, que podem culminar em evitamento, reexperienciação, dissociação ehipervigilância ${ }^{11}$.

Estima-se que 11,5\% dos acidentados de trânsito desenvolvam TEPT ${ }^{12}$. Outro estudo, que investigou três milhões de pessoas envolvidas em acidentes rodoviários, estimou que entre 8 e 40\% das mesmas terão transtorno de estresse pós-traumático no primeiro ano após o acidente ${ }^{13}$. M ayou et al. ${ }^{14}$ detectaram em vítimas deacidentes detrânsito a ocorrência das seguintes perturbações: ansiedade fóbica a viagens ( $52 \%$ ); ansiedade generalizada (58\%), transtorno de estresse pós-traumático $(50 \%)$ e depressão ( $39 \%)$.

Existem diversos fatores ${ }^{3-5}$ que influenciam a forma de ocorrência do estresse ligado ao acidente de trânsito:

. pré experiência: exposições anteriores a fatores adversos podem sobrecarregar a defesa do organismo, desregulando o sistema de regulação do estresse, deixando-o mais vulnerável a reações agudas de estresse ou ao transtorno do estresse pós-traumático;

- peri-experiência: o momento do acidente, a gravidade da ameaça e as circunstâncias do resgate podem amenizar ou agravar o impacto do mesmo;

. pós-experiência: a mobilização de recursos pessoais (coping), senso de auto-eficácia, sentimentos de esperança e significado para a vida, competências val orizadas por si e pelos outros, erecursos sociais (oportunidades para aprender e evoluir, recursos socioeconômicos) poderão minimizar ou agravar as consequências e sequelas do acidente.

Assim, o impacto do acidente de trânsito incide em diferentes graus e afeta desigualmente as vítimas.

\section{Fatores de proteção e fatores de risco}

Há pessoas mais vulneráveis para viverem situações de trauma do que outras ${ }^{3,6-9}$. Observa-se entre os fatores de risco que, quanto pior for a história pregressa da pessoa, quanto maior for sua exposição à violência ou a formas crônicas de sofrimento ao longo da vida, mais grave será sua reação ao estresse intenso e maior será o risco de desenvolver perturbação mental. Vítimas de violência doméstica, vítimas de maus-tratos, abuso ou negligência nos primeiros anos de vida, pessoas com história de estresse acumulado, terão o sistema de regulação do estresse alterado, o que vai comprometer a chance de uma resposta adequada ao estresse.
Por outro lado, há pessoas que vão lidar meIhor com as experiências negativas ${ }^{3,-9}$, quedemonstrarão mais competência, maior auto-estima, sentimentos de auto-eficácia, revelando-se mais positivas em relação à vida, com capacidade de dar significado às experiências. Os fatores protetorese resilientes são aqueles que amenizam a reação ao estresse, reduzem a chance de perturbação e podem atégerar o "crescimento pós-traumático", com mudanças de valores e uma nova atitude de maior valorização da vida.

A gravidade do acidente também influencia 0 desenvolvimento ou não do transtorno de estresse pós-traumático $3-5,12,14$. Avalia-se a gravidade do acidente tal como a pessoa o descreve, por exemplo, quantas pessoas ficaram envolvidas, quantas ficaram gravemente feridas, quantas morreram, o lugar ocupado no acidente, entre outros. 0 fato de a pessoa ser passageiro ou condutor afeta sua percepção do acidente. Ser passageiro, por exemplo, é pior porque passageiros normal mente não se apercebem tão rapidamente da situação e, mesmo quando se apercebem, não têm controle sobre a situação. 0 impacto traumático depende de como a pessoa avalia o quanto sua vida esteveem risco naqueleacidente, uma apreciação inteiramente subjetiva.

\section{Tipos de estresse}

Entreos tipos de estresse ${ }^{3,6,7}$, a dissociação peritraumática éo primeiro sinal de perturbação mental de um acidente. Em seguida, existem dois tipos de respostas pós-traumáticas: a reação aguda ao estresse, que é natural, normal e ocorre nas primeiras horas e nas primeiras semanas após o acidente e, posteriormente, o transtorno do estresse pós-traumático (TEPT).

Tanto a reação aguda ao estresse quanto 0 transtorno de estresse pós-traumático (TEPT) constituem perturbações contempladas no $\mathrm{M}$ anual Diagnóstico e Estatístico de Transtornos Mentais (DSM-IV-TR) ${ }^{11}$.

Quando uma pessoa percebe o momento do acidentecomo muito perigoso, ela poderá viver uma dissociação peri-traumática, sentindo-se robotizada ou fora da cena traumática, como se estivesse num filme, o que poderá trazer perturbação mental uma vez que a dissociação éuma defesa quetem o custo de "desintegrar processos mentais".

A reação aguda ao estresse é a resposta mais comum e conhecida, como dificuldade de adormecer, acordar várias vezes à noite, uma sensação de lembrar das mesmas coisas dias e noites, algo difícil de ser evitado. É natural que nos primeiros dias após um acidente não se tenha vontade de 
andar de carro ou de outro meio de transporte, haja sintomas de ansiedade, dificuldades de respirar, batimentos cardíacos mais acelerados, agitação, dificuldade de ter apetite ou ter o sono ou o apetite desregulados.

0 transtorno do estresse pós-traumático apresenta dezessete sintomas que se dividem em três grupos:

. sintomas intrusivos - reexperiência do acontecimento traumático (memórias perturbadoras e intrusivas do acontecimento; sonhos perturbadores e recorrentes acerca do acontecimento; atuar ou sentir como se 0 acontecimento traumático estivesse ocorrendo novamente, levando a pessoa a reviver a experiência traumática; mal-estar psicológico intenso diante de um estímulo que simbolize 0 acontecimento traumático; reatividade fisiológica quando diante de pistas internas ou externas);

. sintomas de evitamento e embotamento- evitamento deestímulos elugares associados ao trauma eembotamento da reatividadegeral, interessee afeto diminuídos (evitar pensamentos associados ao trauma; evitar atividades, lugares ou pessoas que lembrem o trauma; incapacidade para lembrar aspectos importantes do trauma; interesse diminuído de participar de atividades significativas; sentir-sedesligado ou estranho em relação aos outros; incapaz de gostar dos outros; expectativas encurtadas em relação ao futuro (não esperar ter uma carreira, casamento, filhos ou ter um desenvolvimento normal de vida);

- sintomas de ativação aumentada - ativação aumentada (dificuldade para adormecer ou permanecer dormindo; irritabilidade ou acesso de cólera; dificuldade de concentração; hipervigilância; resposta de alarme exagerada).

Problemas de diagnóstico

e a importância do diagnóstico diferencial

As primeiras queixas ${ }^{3-5,13,14}$ das pessoas depois de um acidente rodoviário são dificuldade de concentração e memória, menor funcionamento intelectual, menor capacidade de diferenciar o queéou não importante, demanter autocontrole, com lembranças recorrentes do acidente e, muitas vezes, sentimentos de culpa pelo acidente. Isso traz um custo laboral significativo, pois muitos desses indivíduos ficam sem condições de trabalhar. $\mathrm{Na}$ prática, algumas pessoas passam a viver "embruIhadas no acidente rodoviário"3.

Contudo, a falta de clareza sobre os critérios para se estabelecer o diagnóstico e o diagnóstico diferencial com outras patologias faz com que, muitas vezes, os sintomas de pessoas com TEPT não sejam reconhecidos e permaneçam sem o tratamento adequado, com agravamento do quadro, vivência de incompreensão e vergonha diante do desajustamento sentido.

Isso evidencia a necessidade de se treinarem as equipes de saúde para o diagnóstico comum e 0 diagnóstico do estresse pós-traumático e suas respectivas comorbidades. 0 diagnóstico e 0 tratamento feitos de modo adequado poderão melhorar 0 atendimento às vítimas de acidentes de trânsito e seus familiares, devendo também ser estendido às equipes de salvamento e resgate.

De acordo com DSM -IV-TR ${ }^{11}$, para se diagnosticar os sintomas do TEPT, énecessário a ocorrência dos seguintes sintomas:

. Sintomas intrusivos (pelo menos um sinto$\mathrm{ma)}$;

. Sintomas deevitamento eembotamento (pelo menos três sintomas);

. Sintomas de ativação aumentada (pelo menos dois sintomas).

Em termos de gravidade ${ }^{3-5}$, nos sintomas intrusivos, há pessoas que todas as vezes que dormem têm a imagem do acidente, o queéal go extremamente perturbador porque, nesse caso, a pessoa vive no acidente. Nos sintomas de evitamento, há pessoas traumatizadas pela mortetrágica deuma criança num acidente, por exemplo, quenão conseguem falar sobre a experiência, pois o sofrimento associado a esta memória é tão perturbador que a fala torna-se intolerável. Como consequência, elas não conseguem falar ou ter um interlocutor para falar, não elaboram uma narrativa, não saem do passado, não se organizam em termos de memória, ficando sempre perturbadas por isso. Nos sintomas de ativação aumentada, observa-se uma resposta da ativação exagerada como raiva e hipervigilância. É comum para quem trata dessas pessoas por vezes sentir medo, pois elas podem ter reações explosivas, muito rapidamente perdendo a calma e muito frequentemente usando armas.

Estima-se que $80 \%$ das pessoas com TEPT tenham outras morbidades associadas, sendo a depressão a perturbação mais frequente ${ }^{3,6-9}$. Diferenças de gênero situam as mulheres com perturbações de pânico eagorafobia e os homens com mais abuso e dependência de álcool e drogas. Segundo os critérios diagnósticos do DSM -IV-TR ${ }^{11}$, há as seguintes perturbações associadas ao trauma: dificuldades na modulação do afeto; comportamento autodestrutivo ou impulsivo; sintomas dissociativos; queixas somáticas, sentimentos de ineficiência; vergonha, desespero, desânimo, hostilidade; isolamento social, sentimento de ameaça constan- 
te, dificuldades derelacionamento; perdas devalores, mudanças de personalidade.

\section{Vítimas}

As vítimas dos acidentes de trânsito vão muito além das diretamente envolvidas no acidente ${ }^{3-5}$. Sobreviventes primários são as vítimas submetidas ao nível máximo de exposição; sobreviventes secundários são os familiares próximos das vítimas; vítimas de terceiro grau são os profissionais que atuam na emergência e no socorro às vítimas; vítimas de quarto grau são pessoas da comunidade envolvidas com o acidente, repórteres, pessoas do poder público; vítimas de quinto grau são aquelas que sofrem o estresse pelo que vêem ou pelo que tomam conhecimento através da comunicação social.

0 impacto do acidentee suas consequências na vítima atingem desigualmente os familiares, podendo afetar a saúde do grupo familiar, comprometendo ou fortalecendo a rede social para enfrentamento do problema $a^{3,7-9,12}$.

Os transtornos dos acidentes e o modo como eles foram enfrentados pela equipe de saúde (médicos, enfermeiros) ou pela equipe de resgate (corpo de bombeiros, policiais rodoviários) também podem afetar a saúde desses profissionais, o que corrobora a necessidade de se investir no "cuidado dos cuidadores" 3 .

M uitas dessas pessoas vão precisar de uma intervenção psicológica focada em ajudá-las a dar sentido a suas vidas, buscando ressignificar o que a experiência traumática Ihes ensinou acerca da vida, bem como suporte social e oportunidades para aprender a lidar com a situação.

Projetos e pesquisas sobre estresse pós-traumático e acidentes de trânsito: ações sugeridas e/ou implantadas

No Brasil, o arcabouço legal referente à prevenção de acidentes está contido basicamenteem um artigo do Código de Trânsito Brasileiro ${ }^{15}$ e em um decreto ${ }^{16}$. 0 artigo 78 da Lei $n^{0} 9.503$, de 23 de setembro de 1997 (Código de Trânsito Brasileiro), dispõe que, por meio do Seguro Obrigatório de Danos Pessoais causados por Veículos Automotores de Vias Terrestres (DPVAT), os M inistérios da Saúde, da Educação e do Desporto, do Trabalho, dos Transportes e da Justiça, por intermédio do Conselho Nacional de Trânsito, deverão desenvolver e implementar programas de prevenção de acidentes.
0 Decreto ${ }^{\circ} 1.017$, de 23 de dezembro de 1993, aloca $50 \%$ do valor total do prêmio do DPVAT ao Fundo Nacional de Saúde; 90\% deste montante destinam-se à prevenção e atendimento às vítimas de acidentes de trânsito e 10\%, ao repasse mensal para o coordenador do Sistema Nacional de Trânsito - Departamento Nacional de Trânsito (DENATRAN) - para aplicação exclusiva em programas de prevenção.

Baseado nesta fundamentação legal, o Programa de Redução da M orbimortalidade por Acidentes de Trânsito (PRM MAT) entrou na pauta de ações do M inistério da Saúde (MS), inicialmente pela Secretaria de Assistência à Saúde e posteriormente pela Secretaria de Vigilância em Saúde e, a partir do repasse dos recursos do DPVAT, passou a haver nos últimos anos uma inédita aplicação dos recursos deste seguro em ações para as quais el e sempre havia sido destinado ${ }^{17}$.

Assim, em 2001, al guns encontros foram realizados em Brasília e em alguns municípios do país, com os representantes do M inistério da Saúde e das Secretarias Estaduais e Municipais de Saúde, com o objetivo de estimular o desenvolvimento e implantação de um programa destinado à prevenção dos acidentes de trânsito no âmbito da saúde. Os gestores da saúde foram instados a elaborar e negociar seus projetos locais, focalizando principalmente ações de capacitação para os profissionais envolvidos com o tema do trânsito de diversas instituições e setores, além da melhoria, implantação e integração dos sistemas de informações sobre acidentes de trânsito nos municípios, com vistas ao monitoramento e vigilância desses eventos.

O montante, inicialmente dequinze milhões de reais, foi reduzido a cinco milhões, tendo sido restringida a abrangência do projeto a apenas cinco cidades (São Paulo, Curitiba, Belo H orizonte, Recife e Goiânia). Tais municípios foram escolhidos porquejátinham algum foco nas ações de prevenção aos acidentes de trânsito, possuíam sistemas de informação bem instalados e massa crítica para análise dessas informações. No ano de 2004, o projeto teve uma ampliação, incluindo mais onze municípios. Em 2005, estes novos municípios passaram a desenvolver suas ações locais de prevenção aos acidentes de trânsito. Também neste mesmo ano, a Organização Pan-Americana de Saúde criou uma área específica para tratar a questão dos acidentes de trânsito na América Latina.

Importantes estudos têm sido feitos no sentido de mapear os custos sociais e econômicos dos acidentes de trânsito no Brasil sob a liderança do I pea, e no sentido de acompanhar os programas 
de preven ção de acidentes em diferentes regiões do país (Claves) ${ }^{18}$. 0 estudo mais recente do I pea ${ }^{2}$, que quantificou os custos dos acidentes nas rodovias brasileiras, apontou para a necessidade de se conhecer o impacto dos acidentes na saúde e na vida das vítimas direta ou indiretamente envolvidas com o acidente, como é o caso dos familiares, e das equipes de resgate e de saúde, estas últimas diretamente afetadas pelo estresse, tendo quelidar com efeitos adversos dos desastres, os riscos de vida e as mortes em circunstâncias trágicas.

A literatura internacional dispõe de uma vasta produção sobre essa temática'19-25, como é o caso do Journal of Traumatic Stress, quejá existe há vinte anos, desde Chernobyl, eque ganhou maior re levância após a derrubada das Torres Gêmeas em 11 de setembro nos Estados Unidos.

$\mathrm{Na}$ Suécia, por exemplo, existem pesquisas e investimentos para diminuição dos custos sociais do estresse pós-traumático, investigando-se as seguintes variáveis: sequelas físicas, sequelas psicológicas, afastamento do trabalho, necessidade de ajuda do Estado e mudanças na situação profissional ${ }^{3}$. Na União Européia, há estudos com vítimas efamiliares querevelam impactos e consequências na vida pessoal, como divórcio, mudança de casa, envolvimento com álcool e drogas 7,25 .

Já o Brasil carece de estudos sistematizados sobre o tema no escopo aqui pretendido. A Revista Brasileira de Psiquiatria, Suplemento 1 de 2003, tem uma edição especial sobre estresse pós-traumático ${ }^{26-29}$. A Biblioteca Virtual da USP dispõe de um grande leque de referências sobre o tema; 0 Hospital das Clínicas de Porto Alegre desenvolve estudos sobre o tema na área da psiquiatria.

Porém, nenhum dos estudos nacionais sobre estresse pós-traumático focaliza a especificidade dos acidentes de trânsito.

No Brasil, para se fazer pesquisas relacionadas ao estresse pós-traumático ligado a acidentes de trânsito, pode-se recorrer ao banco de dados $\mathrm{Da}$ tatran, da Polícia Rodoviária Federal, com cerca de meio milhão de envolvidos em acidentes a cada ano (sobreviventes de acidentes e vítimas fatais), ou ainda aos bancos de dados dos Departamentos Estaduais de Trânsito (D etran) edos Departamentos de Estradas de Rodagem (Der), no sentido de se ter acesso aos motoristas e pessoas que se envolvem em acidentes de trânsito, que retornam para uma avaliação médica e psicológica. Há os estudos desenvolvidos pelo Instituto Brasileiro de Estresse da Pontifícia UniversidadeCatólica (PUC) de Campinas; estudos sobre fóbicos do trânsito e sobre aconselhamento psicológico aos envolvidos em acidentes de trânsito desenvolvidos na Universidade Católica Dom Bosco em Campo Grande, $M$ ato Grosso do Sul; assim como estudos sobre transtornos do estresse pós-traumático desenvolvidos pelo Laboratório de Psiquiatria Experimental do Hospital das Clínicas de Porto Alegre.

Além do aspecto humano queenvolve esse tipo de pesquisa, a mesma faz-se necessária pelas seguintes razões:

- hánecessidade deidentificar medidas adequadas de prevenção e promoção da saúde que levem em conta as sequelas invisíveis dos acidentes de trânsito;

. épreciso desenvolver protocolos de avaliação das sequelas psíquicas para efeito da cobertura de planos de seguro;

. é importante quantificar os custos sociais dos acidentes através de estudos qualitativos quecontextualizem o impacto nas vítimas e em seus familiares; - há necessidade detraçar parâmetros para avaliar impactos de difícil quantificação para os indivíduos e para a sociedade, visando nortear políticas públicas;

- a possibilidade de que um programa de prevenção de acidentes de trânsito que leve em conta as diferentes facetas do problema setornetão bemsucedido como o Programa de Prevenção da DSTaids.

As pesquisas no Brasil deverão:

- elaborar estudos exploratórios para definir as principais variáveis e grupos-alvo;

- averiguar junto aos Comitês de Ética as limitações para acesso aos bancos de dados existentes;

- fazer estudos longitudinais, sem ignorar os benefícios dos estudos transversais, verificando a evolução dos sintomas do TEPT;

- buscar financiamentos que permitam o desenvolvimento de pesquisas com follow-up;

- avaliar a comorbidade, incidência de ansiedade, alergia, depressão, alterações da personalidade, entre outras, situando os fatores de risco e de proteção;

- medir o grau de incapacidade funcional das pessoas, o impacto na vida pessoal e social;

. avaliar o impacto do acidente entre os familiares e cuidadores;

- desenvolver estratégias para minimizar os efeitos psicológicos do trauma eformas de cuidar dos cuidadores;

- contextualizar o estudo do TEPT em termos dediversidadecultural, considerando o modo como as pessoas relatam suas doenças e situar diferenças socioculturais, étnicas, de raça, gênero e faixa etária. 
O transtorno do estresse pós-traumático sob a ótica da saúde pública

Com o seminário "Sequelas invisíveis dos acidentes de trânsito", procurou-se dar visibilidade ao tema do transtorno de estresse pós-traumático associado a acidentes de trânsito. Presentes a este fórum estiveram especialistas brasileiros e estrangeiros; técnicos do Ipea; membros do conselho de acompanhamento do projeto; governo federal (M inistério das Cidades/DEN ATRAN; M inistério da Saúde/ Secretaria de Vigilância em Saúde; Polícia Rodoviária Federal; CLAVES/Ensp/Fiocruz, universidades, entidades não governamentais: Associação Brasileira de M edicina de Tráfego (ABRAMET); Associação Nacional de Transportes Públi$\cos$ (ANTP); Confederação Nacional do Transporte (CNT); Organização Pan-Americana da Saúde (OPAS); Sociedade Brasileira de Ortopedia eTraumatologia (SBOTO); e MAPFRE Seguros.

Constatou-se que o tema "Sequelas do trânsito: transtorno do estresse pós-traumático" ainda não está na agenda da saúde e demais áreas ligadas ao trânsito.

Trata-se de um tema que ainda deve ser muito aprofundado, pois seu correto e adequado enfrentamento requer a obtenção de informações confiáveis, ampla revisão da literatura e maior divulgação dos estudos existentes.

No que se refere aos profissionais de saúde, existe todo um trabalho ainda a ser feito no sentido de inserir efetivamente esse tema na agenda da saúde. Poucos profissionais têm o entendimento sobre como diagnosticar etratar do TEPT, inclusive profissionais da saúde mental e psiquiatras. Com isso, prevalece a "invisibilidade" do diagnóstico, ficando difícil medir o perfil epidemiológico e o impacto na saúde pública, bem como propor ações direcionadas às vítimas.

Outro agravanteéque, diante de qual quer comprometimento "sem visibilidade", e que não é reconhecido pela equipe de saúde, as pessoas costumam sentir vergonha por terem esses sintomas. Elas se envergonham de terem perdido o controle de suas vidas em algum momento, depois de passarem por várias unidades de saúde, consultórios, muitas delas com quadros gravíssimos do estresse pós-traumático e que continuam a se agravar; e essas pessoas não estão sendo ajudadas porque não são diagnosticadas corretamente.

Aliado a esses problemas, os sintomas associados ao TEPT podem se apresentar de uma forma extremamente diluída, e parecerem com outros quadros patológicos ${ }^{27-29}$. Então, o sintoma tende a ser tratado de modo isolado, sem uma visão do transtorno como um todo. Ao se focar apenas o sintoma, as pessoas costumam ir para as emergências, são atendidas e medicadas, eenviadas para casa. N esse caso, não existe nem a compreensão global do quadro, nem o acompanhamento sistemático do mesmo. Muitas vezes, o TEPT aparece de modo parcial, com a manifestação de apenas alguns sintomas. M esmo nesses casos, pode haver perturbação suficiente para que haja interferência no funcionamento global do indivíduo de modo incapacitante.

Além disso, muitas vezes há comorbidade associada ao TEPT ${ }^{30}$, como a depressão, a ansiedade, sintomas de despersonalização ou mudança de personalidade, o consumo de álcool e dependência química, quando a gravidade do quadro tende a aumentar. Enquanto não tratar do TEPT, ou seja, do diagnóstico primário, não se consegue consequentemente cuidar das demais morbidades. N estes casos, observa-se muitas vezes o médico procurando sedar o paciente, em vez de efetivamente tratá-lo.

\section{Recomendações para políticas públicas}

Os desafios para as políticas públicas são amplos: garantir um acompanhamento efetivo e eficaz para as vítimas de acidentes e violência de primeiro, segundo e terceiro graus; orientar, treinar ecapacitar os profissionais das diversas áreas da saúde; ope racionalizar os atendimentos necessários nas Unidades Básicas de Saúde, nos Programas de Saúde da Família, nos hospitais eurgências eemergências.

Para tanto, é necessário desenvolver estraté gias para minimizar os efeitos do trauma do acidente e da violência, dando mais suporte, capacitação e estrutura aos locais que recebem as vítimas de acidentes e violências, incluindo um trabalho com os familiares e as equipes de resgate. Além disso, é preciso prestar atenção aos tipos de suporte social que serão oferecidos, tendo como referência a idéia de reforço da rede social da vítima como melhor estratégia.

0 diagnóstico diferencial e as formas de tratamento do TEPT precisam ser difundidas no Sistema Ú nico deSaúde de modo a seampliar o alcance e a adequação do apoio a vítimas de acidentes de trânsito. É necessário, ainda, entender que, após um acidente, as vítimas tendem a avaliar a sua saúde como pior, recorrendo muito mais vezes aos serviços de saúde.

Hánecessi dade deintegração dos diversos bancos de dados, que existem ainda de uma forma muito setorizada (Sistema de Informações de 
M ortalidade - SIM , Sistema de Informações de Internações H ospitalares - SIH , Sistema de Informações Ambulatoriais - SI A; bancos de dados da Polícia Rodoviária Federal, DER e DETRAN), e qualificá-los, a fim de assegurar a qualidade das suas informações.

0 tema dos acidentes deve ser pensando em conjunto com o das violências em geral. Um exemplo de boa experiência desse tratamento articulado entre trânsito e saúde é o praticado em Belo H orizonte ${ }^{18}$. Com uma maior integração desses bancos de dados e uma melhoria do sistema de informações, será possível uma melhor percepção do problema dos acidentes e violências. Será ne cessário avançar no georreferenciamento das informações, delimitando com maior precisão o local do acidentee a prevalência deacidentes em áreas críticas da cidade, para o estabelecimento de medidas de preven ção mais eficazes, melhoria dos trajetos das vias públicas e da sinalização, favore cendo uma reengenharia do trânsito.

Fomentar pesquisas na área também é uma providência importante: divulgar a necessidade de investigação desse tema nas universidades, formar linhas de pesquisa sobre o tema, discutir metodologias adequadas, incentivar o desenvolvimento de estudos qual itativos para que se possa conhecer de perto a realidade brasileira, produzindo uma re flexão no sistema de saúde e nas áreas afins que trabalham com a questão do trânsito, de modo a seestabelecerem políticas embasadas em evidências e aproximação com a realidade. Conhecendo a magnitude do problema, será possível coordenar políticas públicas de um modo mais integrado.

É preciso sensibilizar profissionais de todas as áreas, profissionais da saúde e gestores públicos para se mostrar com evidências a extensão e magnitude das sequelas dos acidentes e violências e a necessidade de uma maior organização para abordagem do tema, fortalecendo projetos existentes, como o Projeto Sentinela do Ministério da Saúde.

A qualificação dos profissionais para o primeiro atendimento às vítimas e os atendimentos continuados torna-se crucial, e estratégica, para minimizar a magnitude do sofrimento humano aqui implicado. É fundamental que a primeira abordagem ainda no local de ocorrência do acidente seja uma abordagem de qualidade, voltada para minimizar os problemas daí decorrentes. 0 momento da notícia sobre as consequências do acidente e suas respectivas sequelas é outro momento crucial e pode ser um fator condicionador para toda a vida, na forma com que a pessoa recebe as informações, como ela as processa e no modo como irá enfrentar os desafios de sua vida dali para frente.
Outro aspecto fundamental é a necessidade de se estabelecerem parâmetros e estratégias de cuidado para as equipes de saúde tanto do pré-hospitalar, quanto da urgência e emergência, para que possam ser devidamenteacolhidos eapoiados dentro da proposta conhecida como "Cuidando dos cuidadores".

É preciso articular estratégias de prevenção eenfrentamento das sequelas dos acidentes de trânsito com o campo da educação para que o tema entre nos currículos escolares, bem como na formação dos profissionais. As universidades devem assumir esse papel de incluir esse tema em seu currículo.

Além disso, a mídia escrita e falada precisa ser mais sensibilizada e convidada a participar de projetos e debates no âmbito desse tema, para que seja uma aliada nas campanhas de prevenção dos acidentes de trânsito.

\section{Conclusões}

0 transtorno de estresse pós-traumático decorrente de acidentes de trânsito é um problema de saúde pública, ainda fora da agenda da área. Por ano, são mais de 500 mil pessoas envolvidas diretamente em acidentes de trânsito só nas rodovias federais. Além dessas, há toda uma cadeia de pessoas indiretamente afetadas pelo acidente, incluindo familiares, pessoal de resgate, profissionais de saúde, bem como as pessoas que sofrem o estresse pelo que vêem ou pelo que tomam conhecimento através da mídia. Trata-se de uma patologia com consequências graves e incapacitantes, e impactos econômicos e sociais.

No Brasil, ainda não existem estudos voltados para o transtorno de estresse pós-traumático decorrente deacidentes. Assim, ainda fal tam estatísticas e dados que permitam avaliar a real exten são do problema, bem como outras informações que possam embasar mais fortemente políticas públicas.

Também entre os profissionais de saúde, há pouco conhecimento (etreinamento) sobreo transtorno de estresse pós-traumático, levando a dificuldades de diagnóstico e de tratamento adequado dessa patologia, que é facilmente confundida com outras comorbidades.

$\mathrm{Na}$ sociedade civil, o desconhecimento das sequelas invisíveis passíveis de serem geradas por acidentes de trânsito leva a dois problemas: muitos dos acometidos pelo transtorno de estresse póstraumático não buscam apoio médico, desconhecendo a patologia, egerando seu agravamento; por outro lado, muitos dos indivíduos não se dão conta das consequências que acidentes de trânsito po- 
dem gerar, além dos danos físicos, agindo de forma irresponsável ou descuidando-se no trânsito.

Para enfrentamento do problema, énecessário considerar os acidentes de trânsito como um problema de saúde pública. É preciso incentivar estudos sobre o assunto; promover treinamento das equipes de saúde e de resgate para melhor diagnóstico e tratamento do transtorno deestresse póstraumático, e trato aos pacientes; além de realizar programas de promoção da saúde, com campanhas educativas e trabalhos de melhoria da segurança viária.

\section{Colaboradores}

SR H addad trabalhou na organização do seminário "Sequelas invisíveis dos acidentes de trânsito" e na concepção teórica do texto. FG Cavalcante trabalhou na revisão bibliográfica, concepção teórica, elaboração e revisão do manuscrito. PA M orita trabalhou na redação e revisão final do texto para apresentação à revista.
Referências

1. Organização Mundial de Saúde. Faces behind figures: voices of road traffic crash victims and their families. Genebra: OM S; 2007.

2. Instituto de Pesquisa Econômica Aplicada, Departamento Nacional de Transportes, Associação Nacional dos Transportes Públicos. Impactos sociais e econômicos dos acidentes de trânsito nas rodovias brasileiras. Brasília: I pea/Denatran/Antp; 2006.

3. Maia AC, Pires TSF. 0 impacto psicológico da adversidade - o caso dos acidentes rodoviários [apresentação no seminário "Sequelas invisíveis dos acidentes de trânsito"; transcrição em fita-cassete]. Brasília; 2006.

4. Pires TSF, Maia AC. Acidentes rodoviários: Incidência de PTSD nas vítimas directas. In: Actas do 60 Congresso Nacional de Psicologia da Saúde; 2006; Faro. p. 811-817.

5. Pires TSF, Maia AC. O impacto psicológico de acidentes rodoviários nas suas vítimas. I berpsicología: Revista Electrónica de la Federación española de Asociaciones de Psicología [periódico na Internet] 2005; 10(2). Disponível em: http://www.fedap.es/IberPsicologia/ marcoip.htm

6. Maia AC. Emoções e sistema imunológico: um olhar sobre a psiconeuroimunologia. Psicologia, Teoria, Investigação e Prática 2002; (2):2007-2225.

7. Maia AC. Epidemiologia da perturbação do stress traumático (PTSD) e avaliação de resposta ao trauma. In: Pereira M G, Ferreira JM, organizadores. Stress traumático: aspectos teóricos e intervenção. Lisboa: Climepsi; 2003. p. 35-54.

8. Maia AC. Trauma, PTSD e Saúde. In: Pires LCM organizador. Stresse Pós-Traumático - Modelos, Abordagens e Práticas. 2006. Disponível em: http:// www.adafa-portugal.com/livros/Livro_stress.pdf

9. Carvajal C, Carbonell CG, Philippi R, Monteverde P, Bacigalupo F, Alvear F. Características clínicas Del transtorno de adaptación con sintomas de estrés postraumático. Rev Chil Neuro-Psiquiat 2001; 39(2):99-109.

10. Montt ME, Hermosilla W. Transtorno de estrés posttraumático em niños. Rev Chil Neuro-Psiquiat 2001; 39(2):110-120.

11. American Psychiatric Association. M anual Diagnóstico e Estatístico de Transtornos M entais. 4a ed. Porto Alegre: Artmed; 2002. 
12. Norris FH. Epidemiology of trauma: frequency and impact of different potentially traumatic events on different demographic groups. J Consult Clin Psychol 1992; 60(3):409-418.

13. Blanchard EB, Hickling EJ, Taylor AE, Buckley TC Loos WR, Walsh J. Effects of litigation settlements on posttraumatic stress symptoms in motor vehicle accident victims. J Trauma Stress 1998; 11(2):337-354.

14. Mayou R, Bryant $B$, Ehlers A. Prediction of psychological outcomes one year after a motor vehicle accident. Am J Psychiatry 2001; 158(8):1231-1238.

15. Brasil. Lei no 9.503 de 23 de setembro de 1997. Institui o Código de Trânsito Brasileiro. Diário O ficial da União 1997; 24 set.

16. Brasil. Decreto n 1.017 de 23 de dezembro de 1993. Dispõe sobre a arrecadação e o recolhimento da parcela do seguro obrigatório de que trata o parágrafo único do art. 27 da Lei $\mathrm{n}-8.212$, de 24 de julho de 1991. Diário Oficial da União 1993; 24 dez.

17. Souza ES, Minayo MCS, Franco LG. Avaliação do processo de implantação e implementação do Programa de Redução da M orbimortalidade por Acidentes de Trânsito. Epidemiol Serv Saúde 2007; 16(1):19-31.

18. Centro Latino-Americano de Estudos da Violência e Saúde Jorge Carelli. Experiências exitosas de prevenção da violência. Relatório final. Rio de Janeiro: Claves/ EN SP/Fiocruz; 2006.

19. Blanchard EB, Hickling EJ, Forneris CA, Taylor AE, Buckley TC, Loos WR, Jaccard J. Prediction of Remission of Acute Posttraumatic Stress Disorder in Motor Vehicle Accident Victims. J Trauma Stress 1997; 10(2):215-234.

20. Blanchard EB, Hickling EJ, Taylor AE, Buckley TC, Loos WR, Walsh J. Effects of litigation settlements on posttraumatic stress symptoms in motor vehicle accident victims. J Trauma Stress 1998; 11(2):337-354.
21. Blanchard EB, Hickling EJ, Galovski T, Veazey C. Emergency room vital signs and PTSD in a treatment seeking sample of motor vehicle accident survivors. J Trauma Stress 2002; 15(3):199-204.

22. Harvey AG, Bryant RA. Predictors of acute stress following motor vehicle accidents. J Trauma Stress 1999; 12(3):519-525.

23. Bryant RA, Harvey AG, Guthrie RM, Moulds ML. Acute psychophysiological arousal and posttraumatic stress disorder: a two-year prospective study. J Trauma Stress 2003; 16(5):439-443.

24. Stewart $A E$, Lord JH. M otor vehicle crash versus accident: a change in terminology is necessary. J Trauma Stress 2002; 15(4):333-335.

25. Baldo V, Marcolongo A, Floreani A, Majori S, Cristofoletti $M$, Zotto $A D$, Vazzoler $G$, Trivello R. Epidemiological aspect of traumatic brain injury in Northeast Italy. European Journal of Epidemiology 2003; 18:1059-1063.

26. Schestatsky S, Shansis F, Ceitlin LH, Abreu PBS, Hauck S. A evolução histórica do conceito de estresse pós-traumático. Rev. Bras. Psiquiatr. 2003; 25:8-11.

27. Berlim MT, Perizzolo J, Fleck M PA. Transtorno de estresse pós- traumático e depressão maior. Rev. Bras. Psiquiatr. 2003; 25:51-54.

28. Kapczinski F, Margis R. Transtorno de estresse póstraumatico: critérios diagnósticos. Rev. Bras. Psiquiatr. 2003; 25:3-7.

29. Margis R. Comorbidade no transtorno de estresse póstraumático: regra ou exceção? Rev. Bras. Psiquiatr. 2003; 25:17-20.

Artigo apresentado em 20/04/2007

Aprovado em 07/11/2007

Versão final apresentada em 11/01/2008 